\title{
Lógicas de controle e marcos legais: a proteção no campo da infância e da adolescência
}

\section{Control logic and legal guidelines: the protection in the field of childhood and adolescence}

\section{Lógicas de control y marcos legales: la protección en el campo de la infancia y de la adolescencia}

\author{
Maria Livia do Nascimento* \\ Universidade Federal Fluminense - UFF, Niterói, Rio de Janeiro, Brasil \\ Maria I sabel Rosa da Silva Arello** \\ Universidade Federal Fluminense - UFF, Niterói, Rio de Janeiro, Brasil \\ Gláucia Helena de Paula Santiago*** \\ Universidade Federal Fluminense - UFF, Niterói, Rio de Janeiro, Brasil
}

\begin{abstract}
RESUMO
A pesquisa teve como objetivo colocar em análise os sentidos de proteção, presentes nos documentos reguladores das políticas públicas, destinadas a crianças e adolescentes. Como suportes teórico-epistemológicos utilizamos a história como uma ferramenta de análise e as discussões sobre as relações de saber/poder, proposições trabalhadas por Michel Foucault, e o conceito de situação analisadora da análise institucional, na qual acontecimentos são tomados como disparadores que levam ao questionamento de verdades instituídas e de crenças engessadas. $O$ encontro dessas linhas de pensamento com os documentos oficiais estudados possibilitou 0 levantamento de quatro analisadores: a afirmação da família como o lugar ideal para o cuidado de crianças e adolescentes (analisador família), as lógicas do controle e da vigilância presentes no contemporâneo (analisador controle), as teorias psicológicas do desenvolvimento atreladas à ideia de prevenção, risco e vulnerabilidade da infância (analisador teorias do desenvolvimento) e a força do discurso especialista (analisador especialismo). Para esse relato destacamos o analisador controle. A lógica presente nos discursos de proteção opera através de mecanismos de poder pautados nas noções de vulnerabilidade, risco e periculosidade, criando a necessidade de gestão e de controle de uma parcela específica da população.
\end{abstract}

Palavras-chave: práticas de proteção, produção de subjetividade, controle.

\section{ABSTRACT}

The main goal of this research was to analyze the meaning of protection present in the regulatory documents of the public policy destined to children and youth. As theoretical and epistemological supports were applied history 
as a tool of analysis and the discussions about know/power relations, propositions worked by Michel Foucault, and the concept of analyzer status of institutional analysis in which events are taken as triggers that leads to questioning of instituted truths and stagnant beliefs. The meeting of those lines of thoughts with the official documents that have been studied, enabled the survey of four analyzers: the affirmation of family as being the ideal place for caring of children and teenagers (family analyzer), the logics of control and vigilance set in the contemporary (control analyzer), the psychological theories of development attached to the idea of prevention, risk and vulnerability of childhood (theories of development analyzer) and the power of the specialized speech (specialism analyzer). In this report will be featured the analyzer control. The logic present on the speeches of protection works through mechanisms of power based on notions of vulnerability, risk and dangerousness, creating the necessity of management and control of a specific share of population.

Keywords: practices of protection, production of subjectivity, control.

\section{RESUMEN}

La investigación tuvo como objetivo colocar en análisis los sentidos de la protección presentes en los documentos reguladores de las políticas públicas destinadas a niños y adolescentes. Como soportes teórico-epistemológicos utilizamos la historia como herramienta de análisis y las discusiones sobre las relaciones de saber/poder, propuestas por Michel Foucault, así como el concepto de situación analisadora proveniente del análisis institucional, según la cual acontecimientos son tomados como disparadores que llevan al cuestionamiento de verdades instituidas y de creencias enyesadas. El encuentro de esas líneas de pensamiento con los documentos oficiales estudiados posibilitó el planteamiento de cuatro analisadores: la afirmación de la familia como el lugar ideal para el cuidado de niños y adolescentes (analisador familia), las lógicas de control y de vigilancia presentes en la sociedad contemporanea (analisador control), las teorías psicológicas del desarrollo vinculadas a la idea de prevención, riesgo y vulnerabilidad de la infancia (analisador teorías del desarrollo) y la fuerza del discurso especializado (analisador especialismo). Para este relato destacamos el analisador control. La lógica presente en los discursos de protección opera por medio de mecanismos de poder basados en las nociones de vulnerabilidad, riesgo y periculosidad, creando la necesidad de gestión y de control de una parcela específica de la población.

Palabras clave: prácticas de protección, producción de subjetividad, control.

\section{Introdução}

O presente relato tem como objetivo discutir questões referentes à chamada proteção da infância e da adolescência. Buscando discutir as naturalizações e os saberes instituídos sobre o tema, desenvolvemos, em 2013, uma pesquisa intitulada "Problematizando a proteção no campo da infância e da adolescência".

Tal pesquisa buscou pensar os diferentes sentidos de proteção presentes em alguns documentos oficiais brasileiros que regulamentam a garantia de direitos de crianças e adolescentes e 
suas lógicas de proteção. Para tanto, nos debruçamos sobre a leitura e a análise de textos legais destinados a essa população e promulgados a partir de 1990, ano em que foi publicado o Estatuto da Criança e do Adolescente (ECA). Desde essa data até os dias atuais, outros marcos legais foram sendo construídos dentro da proposta de proteção integral dirigida aos menores de dezoito anos. Alguns deles constam como fonte de dados da nossa pesquisa: 1) Plano Nacional de Proteção, Promoção e Defesa do Direito de Crianças e Adolescentes à Convivência Familiar e Comunitária; 2) Nova Lei da Adoção; 3) Nova Lei de Adoção: Guia Comentado; 4) Ato Executivo 4065/2009, também chamado de Plano Mater; 5) Orientações Técnicas para os Serviços de Acolhimento para Crianças e Adolescentes, publicadas pelo Conselho Nacional dos Direitos da Criança e do Adolescente (CONANDA) e pelo Conselho Nacional de Assistência Social (CNAS).

A criação do ECA, pautado no viés da proteção integral, foi impulsionada, nos anos 1980, por diferentes movimentos sociais, entre eles aqueles que contestavam as práticas de inclusão dos até então chamados menores em estabelecimentos de internação. Através de questionamentos a essa lógica, que se encontrava fortemente arraigada nos dois Códigos de Menores, sancionados em 1927 e em 1979, foi possível produzir rupturas na cultura de internação da população infanto-juvenil.

Em resposta a essa mobilização, foram acrescentados à Constituição Federal de 1988 dois artigos (227 e 228) a fim de que fossem estabelecidas leis que assegurassem o bem-estar de crianças e adolescentes, que a partir de então passaram a ser considerados sujeitos de direitos. A fim de que tais escritas oficiais fossem regulamentadas, o Estatuto da Criança e do Adolescente (ECA), em vigência, foi instituído. Ele define, em seu artigo 4oa a família, a comunidade, a sociedade em geral e o poder público como responsáveis por zelar pela não violação dos direitos “( ...) referentes à vida, à saúde, à alimentação, à educação, ao esporte, ao lazer, à profissionalização, à cultura, à dignidade, ao respeito, à liberdade e à convivência familiar e comunitária" (Brasil, 1990).

Com o ECA, preservar vínculos familiares e comunitários passou a ser considerado fundamental para a estruturação das crianças e dos adolescentes enquanto cidadãos. A fim de buscar assegurar a manutenção de tais laços, através do investimento em políticas públicas, foi publicado, em 2006, o Plano Nacional de Proteção, Promoção e Defesa do Direito de Crianças e Adolescentes à Convivência Familiar e Comunitária. Esse Plano é um dos instrumentos legais que buscam romper com a lógica da institucionalização por meio "da prevenção do rompimento dos vínculos familiares, da qualificação do atendimento dos serviços de 
acolhimento e do investimento para o retorno ao convívio com a família de origem" (p. 13).

Apesar de salientar a importância da convivência familiar e comunitária em nome do que entende por proteção, o documento não dispensa a tutela da vida, o que pode ser evidenciado a partir de inúmeras políticas de prevenção de modos de vida dos ditos vulneráveis, e da afirmação da presença do especialista na dinâmica familiar.

Outro marco legal sancionado com o intuito de intervir nos laços sociais é a Nova Lei de Adoção, de 2009. Ela define os Cadastros Estadual e Nacional de Adoção como os instrumentos responsáveis pelo armazenamento dos dados dos casais pretendentes à adoção, bem como pelo registro das informações de todas as crianças e adolescentes disponíveis a esse processo.

Cabe salientar que os casais incluídos nos cadastros são previamente selecionados e passam por um curso ministrado por profissionais considerados especialistas, a fim de que sejam preparados e habilitados para a adoção. Desse modo, podemos analisar o quanto esses dispositivos permitem ao juiz e à equipe técnica exercerem poder sobre a vida das pessoas envolvidas nesse procedimento jurídico.

Essa legislação dispõe, ainda, sobre a necessidade de reavaliação periódica, por parte do juiz, da situação de cada criança ou adolescente que se encontra nos serviços de acolhimento, seja ele institucional ou familiar, visando não exceder o tempo máximo de dois anos previsto pela legislação.

Para ratificar essas e outras determinações da Nova Lei de Adoção, o Tribunal de Justiça do Estado do Rio de Janeiro promulgou o Plano Mater, em 2009. Esse Plano corrobora com a necessidade de assegurar os princípios da excepcionalidade e da provisoriedade das medidas de acolhimento, conforme postulado pela ECA. Assim, para conferir uma maior agilidade na resolução dos processos de adoção, prevê a realização de audiências concentradas semestralmente.

À Comissão Estadual Judiciária de Adoção (CEJA) é conferida a responsabilidade de realizar visitas e inspeções permanentes aos serviços de acolhimento. Com isso, tem como objetivo manter um banco de dados cadastral e estatístico atualizado acerca da rotina de cada indivíduo acolhido, descrita através de laudos e pareceres, bem como das medidas adotadas pelas equipes interdisciplinares que lá atuam.

Nesse sentido, em nome da eficiência dos processos de adoção, essas práticas são naturalizadas como modo de proteção e o cadastramento torna-se um de seus efeitos. Algumas questões podem ser colocadas: Quais as relações entre vigilância e proteção? Ao produzir práticas e discursos que dizem o que é certo e o que é errado, essa vigilância visa proteger ou controlar? 
Em meio a esse conjunto de marcos jurídicos, foram aprovadas, também no ano de 2008, as Orientações técnicas para os serviços de acolhimento para crianças e adolescentes. Essa diretriz tem como objetivo estabelecer os parâmetros e os princípios para o funcionamento das diversas modalidades de serviço de acolhimento de crianças e adolescentes existente em todo o Brasil. Desse modo, dispõe sobre os norteadores dos atendimentos, os pré-requisitos para seleção, a capacitação e o acompanhamento necessários aos profissionais da equipe técnica, a disposição física adequada ao estabelecimento etc.

\section{Metodologia}

O encontro com os documentos foi utilizado como um dispositivo provocador de análises, de modo a causar um desassossego e uma desarrumação nos lugares prontos que a ideia de proteção ocupava. Acompanhando o pensamento de Michel Foucault, utilizamos a história como ferramenta para problematizar as relações de saberpoder presentes no campo da proteção infanto-juvenil. O uso dessa ferramenta possibilita pensar as relações que foram qualificando determinadas verdades como eternas e históricas, desconsiderando o contexto social e político, sempre datado, que as constituíram, em um processo de contínua elaboração. Portanto, ao levantar situações analisadoras, buscávamos questionar algumas verdades instituídas e localizar os movimentos das múltiplas forças que atravessam as práticas protetivas: entendendo ser o estranhamento uma ferramenta potente para o escape da naturalização, daquilo que é dado como certo e imutável. A cada marco legal estudado, os membros da equipe de pesquisa produziam uma análise individual. Tal procedimento era posteriormente coletivizado no grupo, construindo análises transversalizadas por diferentes olhares.

Além disso, continuando nossa proposta de desnaturalização das práticas instituídas sobre o tema da proteção, entramos em contato com uma bibliografia de temas afins, a saber, abrigamento, família, autonomia, assistência, negligência familiar e produção de subjetividade.

\section{Resultados}

Do conjunto de dados levantados nos marcos legais e nos textos estudados, foi possível construir as situações analisadoras, a partir daquilo que nos saltava aos olhos com mais potência, provocando problematizações. Com tal processo, indagamo-nos sobre quatro situações que nas fontes de dados aparecem como naturalmente 
apropriadas ao campo da proteção infanto-juvenil.

A primeira delas diz respeito à afirmação de que a família é o lugar ideal para o cuidado de crianças e adolescentes, ao que passamos a chamar de "analisador família". Nossos procedimentos de pesquisa encontraram nos documentos uma política de proteção, que pautada em verdades hegemônicas, busca modelar a família ideal, afirmar a vida certa e criminalizar diferenças.

Uma segunda situação analisadora consiste na presença marcante das teorias psicológicas do desenvolvimento, que nos textos embasam as ideias de prevenção, risco e vulnerabilidade da infância. A essa lógica de sustentação de um campo de coerência no qual os processos de crescimento e amadurecimento do indivíduo têm etapas pré-fixadas e definitivas a serem seguidas, que se apresentam como deformação quando há escapes, chamamos de "analisador teorias do desenvolvimento".

$\mathrm{Na}$ sequência de nossas análises foi possível destacar outro acontecimento que nos pôs a pensar e ao qual convencionamos chamar "analisador especialismo". Ele refere a força do discurso especialista que atravessa o material estudado ao afirmar, por meio do discurso científico, normas disciplinares e padrões de modos corretos de vida. Os textos valorizam os especialistas enquanto peritos que, através de seus discursos de verdade, conferem essências aos indivíduos.

Por fim, um outro destaque se fez e passamos a chamá-lo de "analisador controle". O procedimento de vigilância contínuo tão típico do mundo contemporâneo também atravessa os marcos legais. Nesse processo, afirmam um olhar observador e investigativo que consagra práticas de vigilância e define modos seguros de proteção, ao mesmo tempo em que perscruta, nas minúcias do comportamento, os indícios de anormalidade.

Esse conjunto de analisadores trouxe inúmeras possibilidades de problematização. Entretanto, para o presente relato de pesquisa apenas o analisador controle será aprofundado. Tal escolha se dá tendo em vista a força que assume atualmente o governo das condutas pela prática da gestão dos riscos. Sob a justificativa, dita bem intencionada, da proteção ou da prevenção dos riscos, tem-se a perspectiva da correção social e da promoção do chamado desenvolvimento humano. Dessa maneira, controle e tutela estão sempre presentes, sendo mais ou menos explícitos em serviços que dão forma às políticas públicas de assistência e proteção à infância e ao adolescente, a partir das legislações que as sustentam. 


\section{Discussão}

A pesquisa aponta que a lógica presente nas chamadas práticas de proteção está intimamente ligada a movimentos de controle, vigilância e prevenção de riscos. A fim de que tais práticas sejam operacionalizadas, os atores que constituem o chamado Sistema de Garantia de Direitos são convocados a manter uma atitude de alerta e a denunciar ações e/ou omissões que possam ser consideradas violadoras dos direitos fundamentais das crianças e dos adolescentes. Nessa função se enquadram diretores de escola, conselheiros tutelares, médicos e demais profissionais de saúde, professores, psicólogos, assistentes sociais, dentre outros profissionais.

A partir desse pano de fundo nos perguntamos sobre o modo sutil por meio do qual o controle se faz para uma parcela específica da população, os pobres. Ou seja, algumas políticas de Estado acabam sendo especialmente destinadas à chamada inclusão social, a partir de intervenções nas famílias consideradas em perigo ou possuidoras de práticas perigosas, conforme uma analogia da nomenclatura utilizada por Donzelot (2002) ao se referir à infância. Sobre isso, Lemos, Scheinvar e Nascimento (2014) ressaltam:

Estar "em perigo" é uma forma de afirmar a necessidade de proteção na construção de um futuro, abrindo a possibilidade de vida segura. Já ser "perigoso" é a indicação de controle, não das condições de vida, mas da pessoa, do seu corpo. Quem está em perigo tem de ser acudido, quem é perigoso tem de ser controlado e/ou eliminado (p. 162).

Somado a isso, com o surgimento da noção de vulnerabilidade social, ampliou-se ainda mais a possibilidade de agir sobre as famílias pobres. Tais ações buscam intervir sobre o perigo, a fim de diminuir, controlar ou eliminar a presença de fatores de risco. Desse modo, podemos afirmar que atrelada à noção de perigo, encontra-se a necessidade de prevenção, que segundo Hillesheim e Cruz (2008), "é, antes de tudo, vigiar, ou seja, antecipar o surgimento de acontecimentos indesejáveis naquelas populações definidas como portadoras de risco" (p. 195).

Essas considerações permitem pensar que a prevenção contemporânea ganhou novos contornos: se antes estava aliada apenas à existência de um determinado perigo, agora passa a estar ligada, também, à probabilidade do aparecimento de comportamentos indesejáveis nas populações consideradas portadoras de risco. Ou nas palavras de Foucault (1996) “(...) significa que o indivíduo deve ser considerado pela sociedade ao nível das virtualidades e não no nível de seus atos; não ao nível das 
infrações efetivas a uma lei efetiva, mas das virtualidades de um comportamento que elas representam." (p. 85).

Retomando os documentos oficiais analisados, podemos perceber que todos eles buscam descentralizar a responsabilidade do Estado de zelar pelo que denominam de bem comum. Nesse sentido, a Nova Lei de Adoção: Guia Comentado (2010) ratifica essa disseminação do controle e da vigilância, atribuindo a outros estabelecimentos e especialistas, para além do Juízo da Infância e da Adolescência, a função de auxiliar as autoridades judiciárias na proteção integral e prioritária dos direitos da população infanto-juvenil, conforme expresso no art. 28 do citado documento ${ }^{1}$. Para pensar tal questão podemos referir Foucault (2003), ao afirmar que o poder se disseminou e passou a ficar à espreita, pronto para, a qualquer momento, intervir na vida dos indivíduos.

De acordo com o documento Novas Regras da Adoção: Guia Comentado (2010), a legislação que regulamenta a adoção trouxe, ainda, como um de seus dispositivos, o Cadastro Nacional de Adoção, tomado como o principal instrumento de aproximação entre crianças/adolescentes e pessoas ou casais julgados habilitados. Com ele, institui-se que famílias pretendentes à adoção devem ser previamente avaliadas pelo Poder Judiciário, por meio de pareceres dados pela equipe multiprofissional do Juízo. Sendo assim, cabe ao Estado, juntamente com os especialistas, definir se uma nova constituição familiar poderá ou não ocorrer por meio do processo de adoção.

De acordo com o referido documento, o cadastro "evita o comércio, a intermediação indevida e a exploração que poderá daí decorrer" (pp. 4-5). Podemos pensar que, por detrás desse discurso protetor, estão sendo operadas práticas de controle, por exemplo a perda da autonomia da mãe que pretende dar seu filho em adoção.

Outro documento lido, que traz como estratégia central a vigilância, é - Plano Mater (2009a). Para isso, conclama a equipe técnica das instituições de acolhimento a controlar e a registrar de forma contínua e permanente as experiências vivenciadas por cada criança ou adolescente acolhido. Além disso, aponta que a equipe interdisciplinar da CEJA deve visitar e inspecionar periodicamente os estabelecimentos, a fim de melhorar os serviços prestados. Depreendemos, assim, que práticas de controle, registro minucioso e ininterrupto, inspeções e visitas, têm sido mascaradas em nome da proteção integral de crianças e de adolescentes e do bem comum.

Seguindo na mesma direção, as Orientações Técnicas para os Serviços de Acolhimento para Crianças e Adolescentes, publicadas pelo CONANDA e pelo CNAS reforçam a necessidade de uma prática de registro contínua e detalhada sobre a rotina, a vida escolar e a socialização dos que se encontram em acolhimento institucional. De 
acordo com o documento, essa prática protegeria a história de vida da criança e/ou do adolescente acolhido.

O mesmo documento traz, ainda, o caráter de vigilância e de controle presentes em espaços de acolhimento, como a casa-lar. Ao referir a proteção de seus usuários afirma o documento que "tendo em vista o fato de acolher, em um mesmo ambiente, crianças e adolescentes com os mais diferentes históricos, faixa etária e gênero, faz-se necessário que o abrigo mantenha uma equipe noturna acordada e atenta à movimentação" (p. 45). Essa afirmação nos permitiu questionar: não estaria o documento, a partir de tais medidas, buscando o controle até mesmo dos acasos da vida?

Sob o argumento de que determinados eventos são potencialmente prejudiciais ao desenvolvimento integral desses indivíduos em formação, a lógica punitiva se faz presente, mesmo que em doses homeopáticas, porém contínuas. Segundo Deleuze (1992), com o capitalismo financeiro ou pós-industrial, os mecanismos de controle foram intensificados e disseminados. No entanto, tornaram-se, simultaneamente, mais sutis e invisíveis, se comparados com as estratégias de biopoder utilizadas na sociedade disciplinar. Desse modo, a vigilância e o controle tornaram-se deveres de todos.

$\mathrm{Na}$ estratégia disciplinar as instituições buscam a regulação da sociedade a partir de técnicas de exercício de poder que investem no controle do tempo, do corpo, do saber e da vida das pessoas. Poder que instituiu não só a vigilância, mas também a correção. Com a sociedade de controle emergem mecânicas de poder que circulam em todos os espaços, de forma fluida e sofisticada, e a céu aberto, para usar uma expressão trazida por Deleuze (1992). Essa outra modalidade de poder convive com o funcionamento disciplinar, mas tem modulação contínua e atua por autocontrole.

Por essas lógicas, nossas análises avançaram no sentido de problematizar a convocação feita, a partir da promulgação do ECA, aos diversos atores que compõem o chamado Sistema de Garantia de Direitos, no sentido de participarem dessa incumbência de zelar pelos direitos fundamentais das crianças e dos adolescentes. Segundo Passetti (2003), a participação é uma exigência da sociedade de controle, que investe cada vez mais em "extrair o máximo das energias inteligentes, fazer participar, criar condições para cada um se sentir atuando e decidindo no interior das políticas de governo" ( $p$. 30).

Desse modo, no âmbito da proteção à infância e à adolescência, essa participação se faz presente através do mecanismo da denúncia de ações ou omissões, da vigilância, estando essas práticas de controle de perigos virtuais amparadas na seguridade social (Lemos, Scheinvar \& Nascimento, 2014). Essa busca "tresloucada por proteção", conforme designou Castel (2005), essa procura infindável 
de se expor minimamente a riscos, faz com que haja um enorme controle da vida.

Ainda de acordo com Passetti (2003), "vivemos numa sociedade de controle que se afirma, antes de tudo, como sociedade de difusão de direitos" (pp. 31-32). Daí um investimento na lei, na criação de um arcabouço legal que dê conta da proteção, mas nos moldes da sociedade da norma, que agencia a produção de condutas esperadas e remete a situações por meio das quais a vida pode ser regulada. Aqui convém lembrar que a regulação dos modos de proteção da criança e do adolescente imposta pelos marcos legais é continua e se faz presente a todo momento: visitas técnicas obrigatórias a estabelecimentos de acolhimento institucional, determinações aos pais de como devem se comportar, vigilância da vida pessoal das famílias, tutela dos modos de vida, lógicas punitivas.

Isso nos leva a evocar que essa complexa noção de proteção, na qual nos debruçamos ao longo da pesquisa, está perpassada por inúmeras forças políticas, econômicas, sociais, subjetivas e por práticas ligados às lógicas de prevenção, vigilância, controle dos riscos e da vulnerabilidade, bem como pela produção de conhecimentos e de todo um pessoal técnico especializado no campo do chamado direitos da infância e da adolescência.

\section{Referências}

Brasil. (1990). Lei Federal no 8069, de 13 de julho de 1990. Dispõe sobre o Estatuto da Criança e do Adolescente e dá outras providências. Brasília, DF: Presidência da República.

Brasil. (2006). Plano Nacional de Promoção, Proteção e Defesa do Direito de Crianças e Adolescentes à Convivência Familiar e Comunitária. Brasília, DF: Presidência da República.

Brasil. (2008). Orientações técnicas para os serviços de acolhimento para crianças e adolescentes. Brasília, DF: Conselho Nacional dos Direitos da Criança e do Adolescente e Conselho Nacional de Assistência Social.

Brasil. (2009a). Ato Executivo 4065, de 8 de setembro de 2009. Regulamenta os procedimentos da Comissão Estadual Judiciária de Adoção do estado do Rio de Janeiro e dá outras providências. Rio de Janeiro: Tribunal do Estado do Rio de Janeiro.

Brasil. (2009b). Lei Federal no 12.010, de 3 de agosto de 2009. Dispõe sobre adoção; altera as Leis no 8.069, de 13 de julho de 1990 - Estatuto da Criança e do Adolescente, 8.560, de 29 de dezembro de 1992; revoga dispositivos da Lei no 10.406, de 10 de janeiro de 2002 - Código Civil, e da Consolidação das Leis do Trabalho - CLT, aprovada pelo Decreto-Lei № 5.452, de 1 o de 
maio de 1943; e dá outras providências. Brasília, DF: Presidência da República.

Brasil. (2010). Novas Regras da Adoção: Guia Comentado. Brasília, DF: Associação dos Magistrados Brasileiros.

Castel, R. (2005). A insegurança social: o que é ser protegido? Petrópolis, RJ : Vozes.

Deleuze, G. (1992). Post-scriptum sobre as Sociedades de Controle. In G. Deleuze (Ed.). Conversações, 1972-1990. (pp. 219-226). Rio de Janeiro: Editora 34.

Donzelot, J. (2001). A Política das Famílias (3a ed.). Rio de Janeiro: Editora Graal.

Hillescheim, B., \& Cruz, L. R. (2008). Risco, Vulnerabilidade e Infância: Algumas Aproximações. Revista Psicologia \& Sociedade, 20(2), 192-199.

Foucault, M. (1996). A Verdade e as Formas Jurídicas. Rio de Janeiro: Editora Nau.

Foucault, M. (2003). A Vida dos Homens Infames. In Estratégia, poder-saber. Ditos e escritos IV. Rio de Janeiro: Editora Forense Universitária.

Lemos, F. C. S., Scheinvar, E., \& Nascimento, M. L. (2014). Uma análise do acontecimento "crianças e jovens em risco". Revista Psicologia \& Sociedade, 26(1), 158-164.

Passetti, E. (2003). Anarquismos e Sociedade de Controle. São Paulo: Editora Cortez.

\section{Endereço para correspondência \\ Maria Livia do Nascimento}

Universidade Federal Fluminense

Departamento de Psicologia - Programa de Intervenção voltado às Engrenagens e Territórios e Exclusão Social (PIVETES)

Campus do Gragoatá, Bloco O, 2o andar, Sala 210, CEP 24.210-201, Niterói - RJ, Brasil

Endereço eletrônico: mlivianascimento@gmail.com

\section{Maria I sabel Rosa da Silva Arello}

Universidade Federal Fluminense

Departamento de Psicologia - Programa de Intervenção voltado às Engrenagens e Territórios e Exclusão Social (PIVETES)

Campus do Gragoatá, Bloco O, 2o andar, Sala 210, CEP 24.210-201, Niterói - RJ, Brasil

Endereço eletrônico: bel_arello@hotmail.com

\section{Gláucia Helena de Paúla Santiago}

Universidade Federal Fluminense

Departamento de Psicologia - Programa de Intervenção voltado às Engrenagens e Territórios e Exclusão Social (PIVETES)

Campus do Gragoatá, Bloco O, 2 o andar, Sala 210, CEP 24.210-201, Niterói - RJ, Brasil

Endereço eletrônico: glau_hps@yahoo.com.br

Recebido em: 02/03/2015

Aceito para publicação em: 10/09/2015 
Maria Livia do Nascimento, Maria I sabel Rosa da Silva Arello,

\begin{abstract}
Notas
1 Art. 28 da Nova Lei de Adoção: Guia Comentado: A colocação da família substituta far-se-á mediante guarda, tutela ou adoção, independentemente da situação judiciária da criança ou adolescente, nos termos desta Lei.

* Professora titular do Departamento de Psicologia da Universidade Federal Fluminense, coordenadora do Programa de Intervenção voltado às Engrenagens e Territórios e Exclusão Social (PIVETES), desenvolvido no Departamento de Psicologia e Serviço de Psicologia Aplicada da UFF.

** Graduanda de psicologia da Universidade Federal Fluminense, participante do Programa de Intervenção voltado às Engrenagens e Territórios e Exclusão Social (PIVETES).

*** Graduanda de psicologia da Universidade Federal Fluminense, participante do Programa de Intervenção voltado às Engrenagens e Territórios e Exclusão Social (PIVETES).
\end{abstract}

